\title{
High-temperature stress during drying improves subsequent rice (Oryza sativa L.) seed longevity
}

\author{
Katherine J. Whitehouse ${ }^{1,2}$, Fiona R. Hay ${ }^{1 *}$ and Richard H. Ellis ${ }^{2}$ \\ ${ }^{1}$ T.T. Chang Genetic Resources Center, International Rice Research Institute, Los Baños, Philippines; ${ }^{2}$ School of \\ Agriculture, Policy and Development, University of Reading, Earley Gate, PO Box 237, Reading RG6 6AR, UK
}

(Received 15 June 2017; accepted after revision 21 September 2017)

\begin{abstract}
Post-harvest drying prolongs seed survival in air-dry storage; previous research has shown a benefit of drying moist rice seeds at temperatures greater than recommended for genebanks $\left(5-20^{\circ} \mathrm{C}\right)$. The aim of this study was to determine whether there is a temperature limit for safely drying rice seeds, and to explore whether the benefit to longevity is caused by high-temperature stress or continued seed development. Seeds of two rice varieties were harvested at different stages of development and dried initially either over silica gel, or intermittently $\left(8 \mathrm{~h} \mathrm{day}^{-1}\right)$ or continuously $\left(24 \mathrm{~h}\right.$ day $^{-1}$ ) over $\mathrm{MgCl}_{2}$ at temperatures between 15 and $60^{\circ} \mathrm{C}$ for up to 3 days. Seeds dried more rapidly the warmer the temperature. Subsequent seed longevity in hermetic storage $\left(45^{\circ} \mathrm{C}\right.$ and $10.9 \%$ moisture content) was substantially improved by increase in drying temperature up to $45^{\circ} \mathrm{C}$ in both cultivars, and also with further increase from 45 to $60^{\circ} \mathrm{C}$ in cv. 'Macassane'. The benefit of high-temperature drying to subsequent longevity tended to diminish the later the stage of development at seed harvest. Intermittent or continuous drying at high temperatures provided broadly similar improvements to longevity, but with the greatest improvements detected in a few treatment combinations with continuous drying. Heated-air drying of rice seeds harvested before maturity improved their subsequent storage longevity by more than that which occurred during subsequent development in planta, which may have resulted from the triggering of protection mechanisms in response to high-temperature stress.
\end{abstract}

Keywords: genebank storage, rice, seed drying, seed longevity, seed maturity, temperature stress

\section{Introduction}

The wide diversity of rice germplasm enables it to be cropped over a wide geographical distribution globally

* Correspondence

Email: f.hay@irri.org across temperatures ranging from as cool as $15^{\circ} \mathrm{C}$ to exceeding $40^{\circ} \mathrm{C}$ (Zhang et al., 2005; Wassman et al., 2009). Nonetheless, temperature, particularly extreme values, affects the rate at which crops develop from sowing to maturity, and their yield, which limits their range of cultivation (Evans, 1993). In rice (Oryza sativa L.), duration to maturity, and so crop adaptation, is affected by temperature, photoperiod and possibly diurnal temperature amplitude, with considerable variation amongst genotypes in responsiveness to these environmental variables (Collinson et al., 1992; Yin et al., 1996). Seed set in rice is vulnerable to low temperatures $\left(12-20^{\circ} \mathrm{C}\right)$ during the reproductive phase or to high day $\left(35-38.5^{\circ} \mathrm{C}\right)$ or night $\left(30-35^{\circ} \mathrm{C}\right)$ temperatures in the early reproductive period up to and including anthesis, with considerable variation amongst genotypes in resilience to such temperature stress (Yoshida, 1981; Jagadish et al., 2008; Coast et al., 2015; Martínez-Eixarch and Ellis, 2015). In addition to effects on yield, rice seed quality is also affected by high temperature during seed development, particularly during histodifferentiation and early seedfilling (Ellis et al., 1993; Ellis and Hong, 1994; Ellis, 2011; Martínez-Eixarch and Ellis, 2015).

Seed quality is important for the long-term conservation of germplasm as it affects seed storage longevity in genebanks (Hay and Smith, 2003). Rice seed quality such as ability to germinate, desiccation tolerance and survival period under air-dry storage - begins to be acquired early in seed development and, in favourable environments, continues to improve in planta until late in maturation drying (Ellis et al., 1993; Ellis and Hong, 1994; Ellis, 2011). Moreover, rice seeds, which were metabolically active at harvest $(\geq 16.2 \%$ moisture content), improved considerably (up to 3 -fold in more moist samples) in subsequent air-dry longevity when subjected to initial, intermittent $\left(8 \mathrm{~h}\right.$ day $\left.^{-1}\right)$ hightemperature $\left(45^{\circ} \mathrm{C}\right)$ air-drying ex planta in comparison with immediate post-harvest drying at $15^{\circ} \mathrm{C}$ and $15 \%$ relative humidity (RH) (Whitehouse et al., 2015). This latter drying regime is within the multi-species range of $5-20^{\circ} \mathrm{C}$ with $10-25 \% \mathrm{RH}$ recommended for genebanks (FAO, 2013).

The importance of seed drying in order to extend subsequent seed storage longevity in genebanks is 
well recognized (Cromarty et al., 1982; FAO, 1994, 2013; Rao et al., 2006), but high temperatures are usually avoided to reduce the risk of seed deterioration, especially when seeds have a high moisture content (Nellist, 1980; Cromarty et al., 1982; McDonald and Copeland, 1997). Heated-air seed drying practices recognize safe drying temperatures (maximum value avoiding damage to ability to germinate) which vary with initial moisture content, design of drier, or whether air or seed temperature is specified (Nellist, 1980). However, much of the research involving heated-air seed drying used rewetted mature, dry seeds (Nellist, 1980). Compared with many other species, safe drying temperatures reported for rice seeds are comparatively high: for example, $48.9^{\circ} \mathrm{C}$ at $20 \%$ moisture content or above, $51.7^{\circ} \mathrm{C}$ at $15-20 \%$ moisture content, and as high as $60^{\circ} \mathrm{C}$ for initial seed moisture content of $15 \%$ or below (Lewis, 1950). Harrington (1972) suggested a cooler limit of $45^{\circ} \mathrm{C}$ for drying all cereal seeds, whilst Yamashita (1993) recommended an air temperature of only $40^{\circ} \mathrm{C}$ for rice seeds with $\geq 24 \%$ moisture content. Similarly, Jittanit et al. (2010) reported that rice seeds dried at $40^{\circ} \mathrm{C}$ for $50-250 \mathrm{~min}$ utes showed $>85 \%$ germination, whereas germination was adversely affected at $\geq 60^{\circ} \mathrm{C}$. They also reported less damage from drying in a batch than a fluidized-bed dryer at any one temperature. With traditional sun drying, on the other hand, temperatures can reach up to $52^{\circ} \mathrm{C}$ and if carried out carefully rice seed viability can be maintained well thereafter (Regalado and Brena, 2006).

Many investigations of high-temperature drying in rice relate to milling quality. Drying at high temperatures creates intra-kernel moisture content gradients that can lead to fissure formation and reduced milling yield if seeds cool before tempering (Chen et al., 1997; Cnossen and Siebenmorgen, 2000, 2002; Schluterman and Siebenmorgen, 2007). Hence for milling rice, Lewis (1950) recommended cooler temperatures than for seeds: $40.6^{\circ} \mathrm{C}$ at $20 \%$ or more, $46.1^{\circ} \mathrm{C}$ at $15-20 \%$, and $51.7^{\circ} \mathrm{C}$ for initial seed moisture contents of $15 \%$ or below. More recently, two-stage drying (initial high temperature and high velocity followed by ambient conditions with reduced air flow) has been used to dry high-moisture content seeds to reduce damage to milling yield (Jittanit et al., 2010; and references therein). The beneficial high-temperature procedure for rice seed longevity reported by Whitehouse et al. (2015), as above, was in fact a multi-stage treatment: an initial diurnal cycle $\left(8 / 16 \mathrm{~h}, 45^{\circ} \mathrm{C} / 15^{\circ} \mathrm{C}\right.$ for $1-6$ days) followed by a final period at $15^{\circ} \mathrm{C}(15 \% \mathrm{RH})$.

We report here an investigation of the hightemperature limits for seed longevity when drying rice seeds harvested at different moisture contents and days after anthesis (DAA) in order to explore whether maturing rice seeds, which are still metabolically active at harvest, benefit from high-temperature exposure due to continued development or a stressrelated response ex planta.

\section{Materials and methods}

\section{Plant material}

Seeds of an aromatic variety of rice from the International Rice Genebank Collection, accession IRGC 117265 (McNally et al., 2009), and of a commonly grown indica variety, 'Macassane', were planted for harvest in the 2015 dry season (DS) and 2016 wet season (WS), respectively (Fig. 1A,C). Seeds were sampled either from the International Rice Genebank (IRG) active collection $\left(4^{\circ} \mathrm{C}\right)$ (IRGC 117265; https://doi.org/10.18730/ 1PG6J) or the storage facility $\left(20^{\circ} \mathrm{C}\right.$ and $\left.30 \% \mathrm{RH}\right)$ at the upland site ('Macassane') and held at $50^{\circ} \mathrm{C}$ for 5 days to break dormancy. Staggered sowing of seeds from IRGC 117265 was conducted to enable simultaneous harvests at 25, 35 and 45 days after $50 \%$ anthesis (DAA) on two separate occasions, 13 days apart, to achieve two seed lots per stage of maturity differing in harvest moisture content (Table 1 and Fig. 1A). For 'Macassane', all seeds were sown on 7 June 2016 and harvested on three separate dates at 34, 36 and 38 DAA (Table 1 and Fig. 1C). All seedlings, from both varieties, were raised in a seed bed before being transplanted to plots on the International Rice Research Institute (IRRI) Ziegler Experimental Station (ZES) (14 ${ }^{\circ} 9^{\prime} 3.5742^{\prime \prime} \mathrm{N}, 121^{\circ} 15^{\prime}$ $\left.54.504^{\prime \prime} \mathrm{W}\right)$ and normal rice production practices and plant protection measures were followed. Seeds were harvested in April 2015 and October 2016 for IRGC 117265 and 'Macassane', respectively (Table 1 and Fig. 1A,C).

Immediately after harvest, the seeds of each variety were threshed and blown to remove debris and half-filled grains before they were transported to the laboratory where the seeds underwent manual cleaning - discarding any empty, damaged and/or diseased seeds - and the initial temperature, equilibrium relative humidity $(\mathrm{eRH} ; \%)$ and the moisture content (MC; \% fresh weight) were measured. The eRH was measured at room temperature $\left(21.5^{\circ} \mathrm{C}\right)$ using an AW-D10 water activity station in conjunction with a HygroLab 3 display unit (Rotronic South East Asia, Singapore). Seed MC (fresh weight basis) was determined using three $5 \mathrm{~g}$ samples from each seed lot (harvest $\times$ DAA) using the high-constant-temperature oven method (ISTA, 2013).

\section{Seed drying over saturated $\mathrm{MgCl}_{2}$ (IRGC 117265)}

Seeds of IRGC 117265 at each maturity stage and from $\mathrm{A}$ and $\mathrm{B}$ harvests were divided into $9 \times 200 \mathrm{~g}$ samples and placed into $0.2 \times 0.33 \mathrm{~m}$ (length $\times$ width) nylon mesh bags ( $1 \mathrm{~mm}$ diameter holes) in which they were 


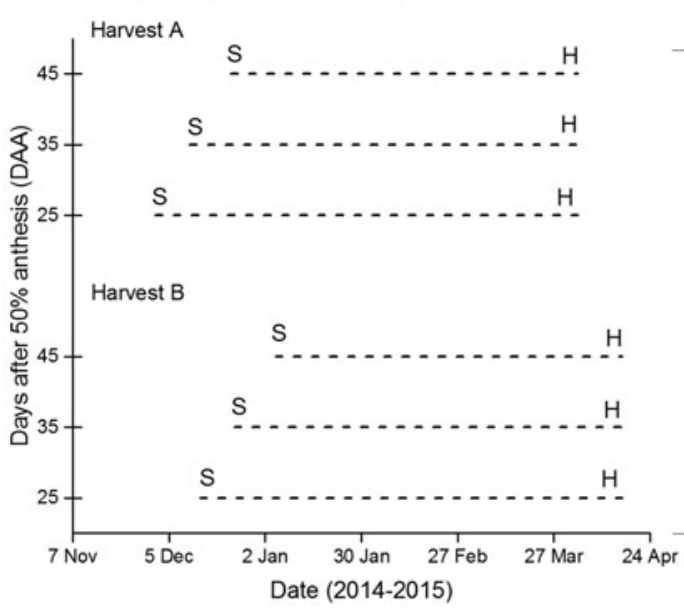

C

Seed production 2016 WS

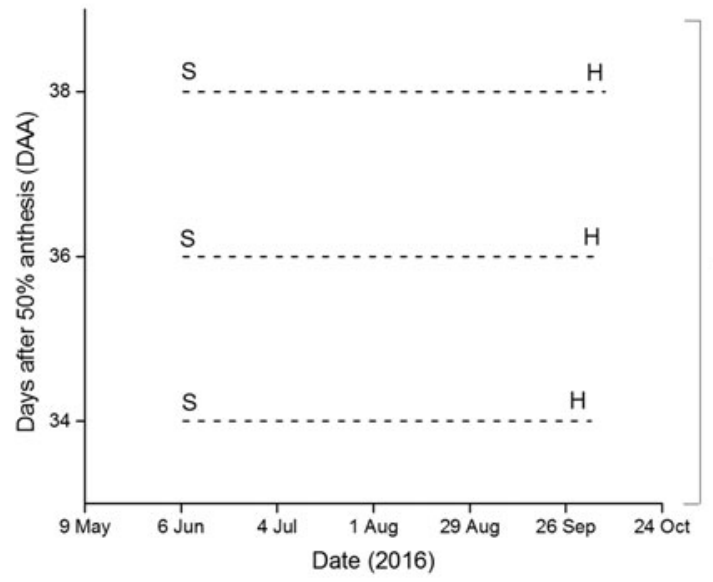

B

Drying treatments $\left(\mathrm{MgCl}_{2}\right)$

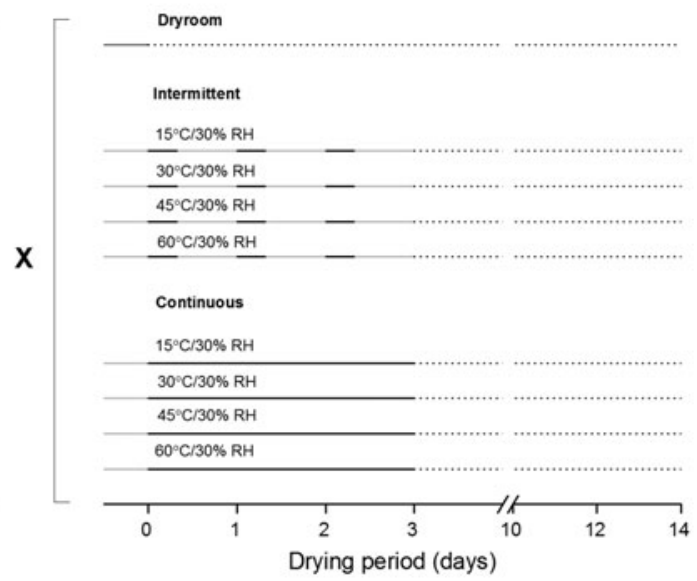

D Drying treatments (silica)

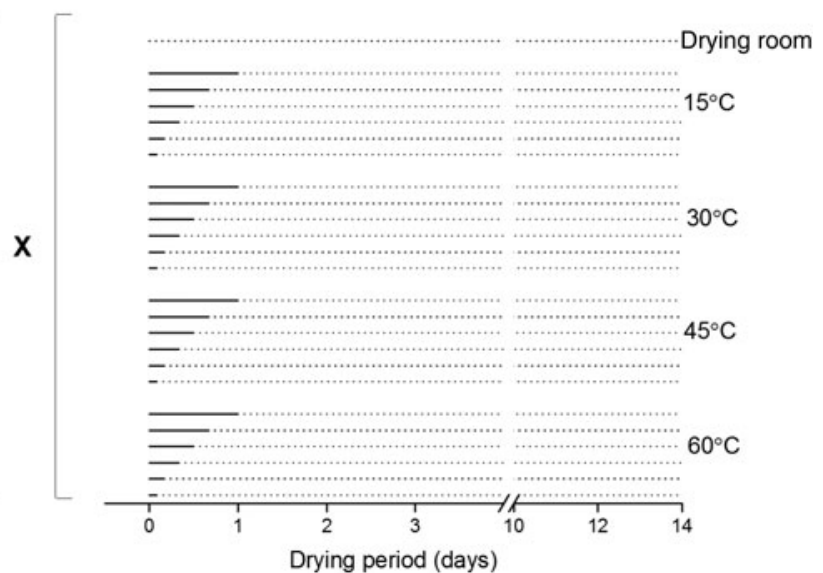

Figure 1. Illustration of the experimental design showing the factorial combination of different seed production and seed drying treatments for rice accession IRGC 117265 (A and B) and cv. 'Macassane' (C and D). Seeds were sown (S) for harvest (H) in either the 2015 dry season (DS) or the 2016 wet season (WS). In graphs B and D the dotted lines represent the drying room $\left(15^{\circ} \mathrm{C} / 15 \%\right.$ $\mathrm{RH})$ and the continuous black lines represent alternative drying conditions. The continuous grey lines show the duration seeds were held in an air-tight box at room temperature $\left(21.5^{\circ} \mathrm{C}\right)$.

stored inside sealed $0.6 \times 0.3 \times 0.132 \mathrm{~m}$ (length $\times$ width $\times$ height) electrical enclosure boxes (ENSTO, Porvoo, Finland) at room temperature $\left(21.5^{\circ} \mathrm{C}\right)$ overnight to limit drying until the treatments began the following morning $(08.00 \mathrm{~h})$. A sample from each maturity stage was transferred directly to the genebank drying room maintained at $15^{\circ} \mathrm{C}$ and $15 \%$ RH (Fig. 1B). As the drying room conditions comply with the current genebank standards (FAO, 2013), the treatments dried throughout therein provided a control, i.e. the baseline against which the effects of other drying treatments were compared. To provide the other drying environments, the remaining seed samples were placed over a $700 \mathrm{ml}$ super-saturated solution of $\mathrm{MgCl}_{2}$ in sealed electrical enclosure boxes, producing an $\mathrm{RH}$ of approximately $30 \%$, and transferred either to the drying room $\left(15^{\circ} \mathrm{C}\right)$ or to incubators at 30,45 or $60^{\circ} \mathrm{C}$ (Fig. 1B). Within these drying environments, there was no airflow through the seeds; rather the drying process was passive with the desiccant absorbing moisture from the seeds, without affecting equilibrium $\mathrm{RH}$ within the container, and the temperature driving the evaporation of moisture from the seeds to their surroundings. Seed samples were exposed to intermittent (Int; $8 \mathrm{~h} \mathrm{day}^{-1}$ ) and continuous (Cont; $24 \mathrm{~h}$ ) drying treatments for 3 days at each temperature regime before final drying for 11 days in the drying room (i.e. equilibrating to $15^{\circ} \mathrm{C} / 15 \%$ $\mathrm{RH}$; expected MC 6-7\%). During the non-active drying phase (Int; 16.00-08.00 h) seeds were sealed in empty (without $\mathrm{MgCl}_{2}$ ) electrical enclosure boxes at $21.5^{\circ} \mathrm{C}$ until the following morning (Fig. 1B). The change in weight and $\mathrm{eRH}$ of samples was monitored daily, at $16.00 \mathrm{~h}$ for intermittently dried seeds and at $08.00 \mathrm{~h}$ for continuously dried seeds, until samples were transferred to the drying room where this was subsequently recorded every 3 days. The dried seeds were then sealed 
Table 1. Dates of sowing and harvest and the seed moisture content (MC) and equilibrium relative humidity (eRH) at harvest of rice accession IRGC 117265 and cv. 'Macassane' harvested 25-45 or 34-38 days after 50\% anthesis (DAA), respectively

\begin{tabular}{|c|c|c|c|c|}
\hline $\begin{array}{l}\text { Accession (harvest)/cultivar and } \\
\text { seed maturity (DAA) }\end{array}$ & Sowing date & Harvest date & $\begin{array}{l}\text { Harvest MC (s.e.m.) } \\
\text { (\% fresh weight) }\end{array}$ & $\begin{array}{l}\text { eRH } \\
(\%)\end{array}$ \\
\hline \multicolumn{5}{|l|}{ IRGC 117265 (harvest A) } \\
\hline 25 & 23 Dec 2014 & 3 Apr 2015 & $23.3(0.1)$ & 96.6 \\
\hline 35 & 11 Dec 2014 & & $18.9(0.1)$ & 86.4 \\
\hline 45 & 1 Dec 2014 & & $18.1(0.0)$ & 86.0 \\
\hline \multicolumn{5}{|l|}{ IRGC 117265 (harvest B) } \\
\hline 25 & 5 Jan 2015 & 16 Apr 2015 & $21.9(0.1)$ & 91.5 \\
\hline 35 & 24 Dec 2014 & & $16.3(0.1)$ & 80.8 \\
\hline 45 & 14 Dec 2014 & & $16.8(0.1)$ & 82.9 \\
\hline \multicolumn{5}{|l|}{ 'Macassane' } \\
\hline 34 & 7 Jun 2016 & 4 Oct 2016 & $32.0(1.2)$ & 99.9 \\
\hline 36 & & 6 Oct 2016 & $23.8(2.0)$ & 96.8 \\
\hline 38 & & 8 Oct 2016 & $20.9(0.3)$ & 91.5 \\
\hline
\end{tabular}

inside $0.16 \times 0.24 \mathrm{~m}$ (length $\times$ width) laminated aluminium foil packets (Moore and Buckle, Saint Helens, UK) and stored at $2-4^{\circ} \mathrm{C}$ until experimental storage began.

\section{Seed drying over silica gel ('Macassane')}

Seeds of 'Macassane' harvested at 34, 36 and 38 DAA were divided into $25 \times 200 \mathrm{~g}$ samples and placed into nylon mesh bags (as described above) (Fig. 1D). A sample was immediately transferred to the drying room $\left(15^{\circ} \mathrm{C}\right.$ with $\left.15 \% \mathrm{RH}\right)$ and the remaining samples were stored inside individual $0.3 \times 0.3 \times 0.132 \mathrm{~m}$ (length $\times$ width $\times$ height) electrical enclosure boxes containing $400 \mathrm{~g}$ of (previously dried) silica gel (granular 0.2-1 $\mathrm{mm}$; Sigma-Aldrich, Singapore). A box was transferred to either the genebank drying room $\left(15^{\circ} \mathrm{C}\right)$ or to incubators at 30,45 and $60^{\circ} \mathrm{C}$ at 10 min intervals (time taken to measure sample $\mathrm{eRH}$; done to ensure all samples were dried for the same period) until there were a total of six boxes at each temperature (Fig. 1D). The change in weight and eRH (as described above) was monitored for each sample after 2, 4, 8, 12, 16, 24, 72, 144, 216, 288 and $336 \mathrm{~h}$. A sample was removed and transferred from each high-temperature regime after 2, 4, 8, 12, 16 and $24 \mathrm{~h}$ to the drying room for final drying (Fig. 1D). At 14 days after harvest, samples from all drying treatments were removed, final weight and eRH of each recorded, before they were sealed inside laminated aluminium foil packets and stored as described above.

\section{Seed storage}

Seed samples were removed from temporary cold storage $\left(2-4^{\circ} \mathrm{C}\right)$ and equilibrated to room temperature $\left(21.5^{\circ} \mathrm{C}\right)$ before opening. Each sample was split into $29 \times 5 \mathrm{~g}$ subsamples which were placed into $30 \mathrm{~mm}$ diameter open Petri dishes in a $\mathrm{VC}^{3}$ 0034-M climate chamber (Vötsch Industrietechnik, Germany) set at $60 \% \mathrm{RH}$ and $21.5^{\circ} \mathrm{C}$ for $4-5$ days. Once equilibrium had been reached (approximately 10.9\% MC), four of the $5 \mathrm{~g}$ subsamples from each treatment combination were removed to measure seed $\mathrm{eRH}$; three of these were then used to determine MC and the fourth to estimate initial ability to germinate. The remaining subsamples (25) were each sealed inside individual aluminium foil packets $(0.12 \times 0.08 \mathrm{~m}$, length $\times$ width $)$ before being placed in an incubator at $45^{\circ} \mathrm{C}$. One packet per treatment combination was removed from storage at $45^{\circ} \mathrm{C}$ at 3-day intervals up to 54 days to test ability to germinate. Moisture content determinations, using three additional $5 \mathrm{~g}$ packets of seeds, were made at the mid-point and end of storage. These analyses confirmed that seed storage moisture content was stable during experimental storage.

\section{Seed germination}

Ability to germinate was estimated with four replicates of 30 seeds, sown on two layers of Whatman no. 1 paper wetted with $7.5 \mathrm{ml}$ distilled water in $90 \mathrm{~mm}$ diameter Petri dishes and incubated at constant $30^{\circ} \mathrm{C}$ ( $12 \mathrm{~h}$ light and $12 \mathrm{~h}$ dark cycle). Germination was scored after 3, 5, 7 and 14 days; seeds were scored as germinated when the radicle had emerged by at least $2 \mathrm{~mm}$. After the test, mouldy seeds were discarded and non-germinated, hard seeds were dehulled and tested for an additional 7 days before final scoring.

\section{Statistical analysis}

Seed survival curves were fitted by probit analysis using GenStat for Windows, version 17 (VSN 
International Ltd, Hemel Hempsted, UK). As seeds from both varieties typically show dormancy, a probit model combining loss of dormancy (during early storage) with loss of viability (Eqn 1) was applied using the FITNONLINEAR directive in GenStat:

$$
g=\left(K_{\mathrm{d}}+\beta_{1} p\right) \times\left(K_{\mathrm{i}}-(p / \sigma)\right),
$$

where $g$ is the ability to germinate in normal equivalent deviates (NED), $K_{\mathrm{d}}$ is the initial proportion of nondormant seeds (NED), $\beta_{1}$ is the probit rate of loss in dormancy and $p$ is the storage period (days); $K_{\mathrm{i}}$ and $\sigma$ are as in the Ellis and Roberts (1980) viability equation:

$$
v=K_{\mathrm{i}}-p / \sigma,
$$

where $v$ is the viability (NED) of a seed lot stored for period, $p, K_{\mathrm{i}}$ is the initial viability (NED) and $\sigma$ (days) is the standard deviation of the normal distribution of seed deaths in time. The time for viability to fall to $50 \%$ ( $p_{50}$, product of $K_{\mathrm{i}}$ and $\sigma$ ) was also estimated and used as a measure of longevity. For those seed lots that showed a reduced initial viability and a systematic pattern of residuals when only fitting Eqn (1), the 'control mortality' parameter ('immunity' in GenStat), which estimates the proportion of 'nonresponding' seeds (i.e. dead or empty) within the population (Mead and Gray, 1999), was included in the probit analysis. Probit analysis was carried out for all seed lots simultaneously, fitting the full model (different estimates for all parameters).

\section{Results}

\section{Seed drying rate}

The harvest eRH of all the seed lots was high (80.8$99.9 \%$; Table 1). For each seed production, the moisture content of seeds harvested at the lowest DAA was highest (21.9-32.0\%). Moisture content reduced with increasing maturity, but sometimes the intermediate sample provided the lowest value: 'Macassane' seeds at 34 DAA were the most moist and IRGC 117265 seeds at 35 DAA (harvest B) the driest (16.3\%). All drying treatments, including the control, provided the characteristic negative logarithmic decline, with progressively more rapid moisture loss as temperature increased from 15 to $60^{\circ} \mathrm{C}$ (Figs 2A-D and 3A). Later harvests, with lower initial MC, showed slower drying rates at all temperatures; this was most apparent at $15^{\circ} \mathrm{C}$. Most of this effect of later harvest date affected moisture loss over the first day only. The pattern of drying of seeds in the drying room was similar to $45^{\circ} \mathrm{C} / 30 \% \mathrm{RH}$ over the first 3 days of continuous drying at all maturity stages (Fig. 2C,D), whereas seeds dried faster at all temperatures over silica gel compared with the drying room (Fig. 3A).

\section{Subsequent seed storage longevity}

Significant differences in survival curves $(P<0.05)$ were apparent between some, but not all, seed lots harvested at different maturity stages and amongst drying treatments at each maturity stage. Therefore, longevity derived from the best-fit survival curves for each treatment combination are shown (Tables S1 and S2).

In both experiments, low-temperature drying $\left(15^{\circ} \mathrm{C}\right)$ resulted in seeds with shorter longevity compared with high-temperature drying (Figs 2E-H and $3 \mathrm{~B}$ ). Nonetheless, drying seeds over $\mathrm{MgCl}_{2}$ at $15^{\circ} \mathrm{C}$ still led to an improvement in their subsequent storage longevity compared with drying at lower $\mathrm{RH}(15 \% \mathrm{RH})$ in the drying room (Fig. 2E-H). In 'Macassane', however, relative improvement between the drying room and silica gel treatments at $15^{\circ} \mathrm{C}$ depended on the duration of drying (Fig. 3B). Drying seeds in the drying room throughout (shown by broken lines) resulted in progressively greater longevity from 25 to 45 DAA in harvest $A$ of IRGC 117265 (Fig. 2E,G), a small increase from 34 to 36 DAA but similar longevity at 36 and 38 DAA in 'Macassane' (Fig. 3B), or an increase from 25 to 35 DAA but then decline from 35 to 45 DAA in harvest $B$ of IRGC 117265 (Fig. 2F,H).

In both varieties at all harvests, the higher the temperature of drying from 15 to $45^{\circ} \mathrm{C}$ the greater the longevity (Figs 2E-H and 3B). In 'Macassane', this was also the case with further increase in temperature from 45 to $60^{\circ} \mathrm{C}$ (Fig. 3B), whereas $60^{\circ} \mathrm{C}$ provided poorer, or sometimes similar, longevity compared with $45^{\circ} \mathrm{C}$ in IRGC 117265 , but was always greater compared with drying at 15 or $30^{\circ} \mathrm{C}$ (Fig. 2E-H). There was a tendency for the more mature seed at harvest to show a slightly smaller benefit to longevity from high-temperature drying.

Within a temperature regime, the longevity of seeds of IRGC 117265 exposed to high temperature intermittently was broadly similar to the equivalent continuous treatment (Fig. 2E-H). At 30 and $45^{\circ} \mathrm{C}$, continuous high-temperature drying provided slightly greater longevity than intermittent drying, but vice versa at 15 and $60^{\circ} \mathrm{C}$ (Fig. 2E-H).

The longevity of seeds of 'Macassane' dried over silica gel was determined for samples drawn after successive periods of drying. This showed that at the warmer temperatures of 45 and $60^{\circ} \mathrm{C}$, and to a lesser extent at $30^{\circ} \mathrm{C}$, the early periods of drying provided greater enhancement of longevity than the later periods (Fig. 3B). Comparing $60^{\circ} \mathrm{C}$ with progressively cooler temperatures, the warmer regimes continued to provide a benefit to longevity later in drying than was observed in cooler conditions. 


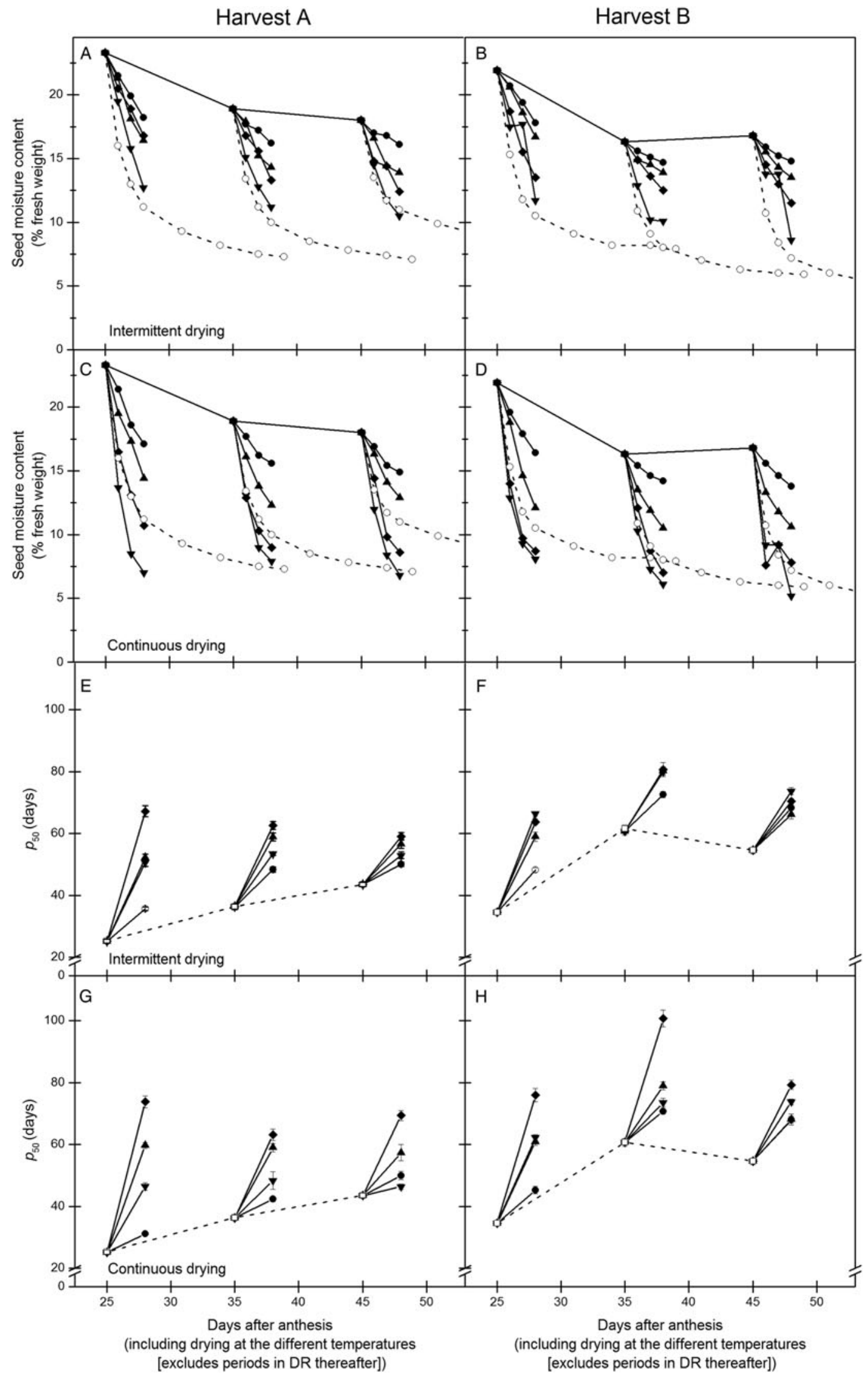

Figure 2. (See next page for legend.) 


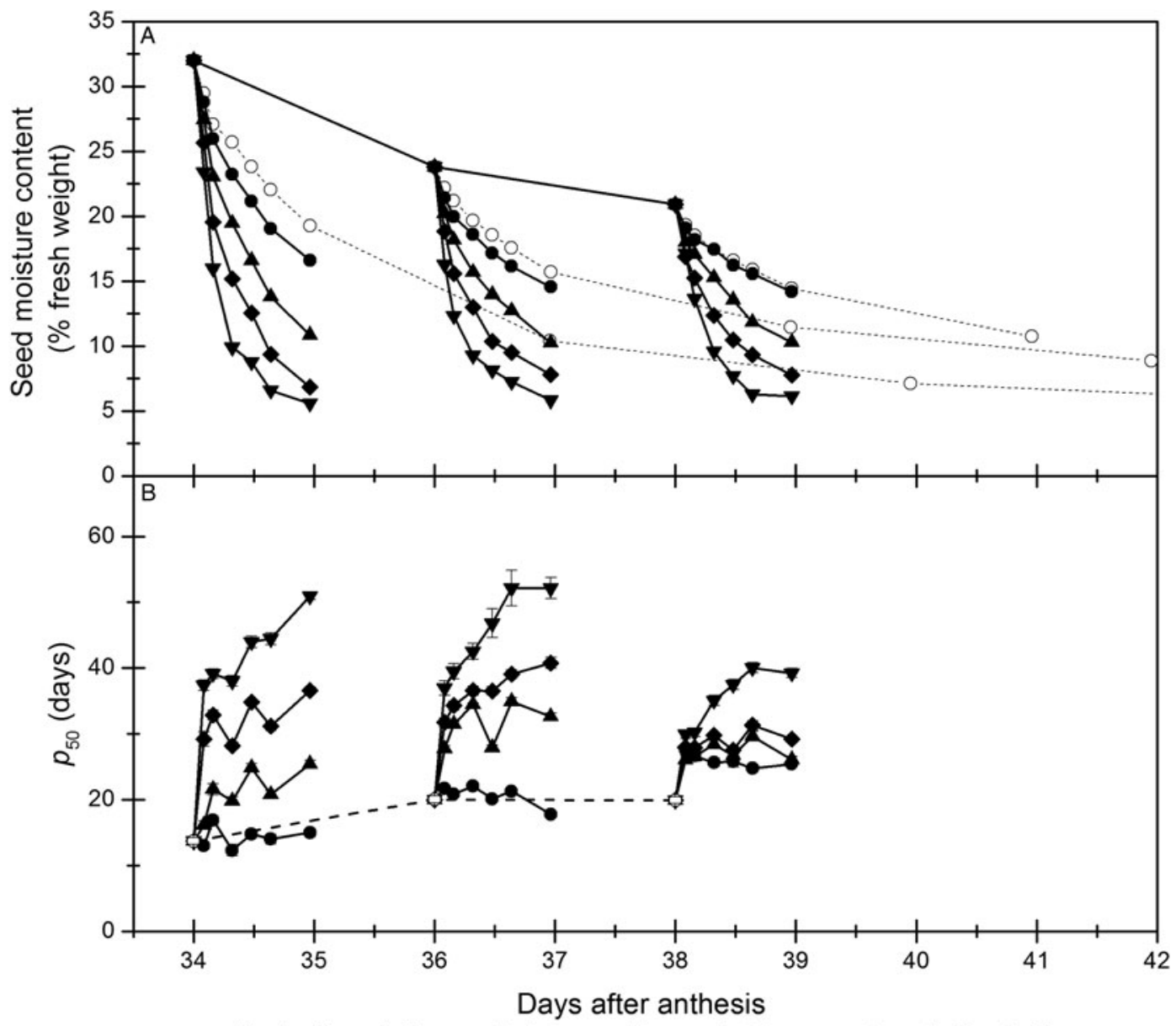

(including drying period over silica gel at temperature indicated)

Figure 3. Seed drying curves (A) at $15(\bullet), 30(\boldsymbol{\Delta}), 45(\bullet)$ or $60^{\circ} \mathrm{C}(\boldsymbol{\nabla})$ over silica gel for rice cv. 'Macassane' seeds harvested at 34 , 36 and 38 days after $50 \%$ anthesis (DAA) during 2016 wet season (WS). Interrupted lines show loss in moisture content for seeds dried throughout in the drying room (DR) control $\left(15^{\circ} \mathrm{C} / 15 \% \mathrm{RH} ; \circ\right)$. Loss in moisture content during drying was estimated based on the initial determination and subsequent change in sample weight. Seed longevity (B) during storage at $45^{\circ} \mathrm{C}$ and $60 \%$ $\mathrm{RH}\left(p_{50}\right.$; days \pm s.e.m.) after each drying treatment (DAA $\times$ temperature $\times$ drying duration), from both harvests, was estimated from the best-fit model for each sample.

\section{Discussion}

The moisture content of mature seeds at harvest depends on the ambient temperature and relative humidity and will affect the subsequent rate of viability loss if seeds are not dried ex planta. In tropical climates, $\mathrm{RH}$ conditions rarely fall below $80 \%$ and so seeds are harvested at moisture contents too high for safe storage, especially in the wet season. The genebank standards recommend drying seeds immediately after harvest to between 3 and $7 \% \mathrm{MC}$ before long-term storage (FAO, 2013), because the rate of ageing is minimized at these values (Ellis et al., 1989, 1992; Ellis and Hong, 2006). However, the tolerance of orthodox seeds to desiccation and storage depends on the stage of maturity and the drying conditions, especially the rate of drying (Hay and Probert, 1995).

Figure 2. Seed drying curves (A, B, C, D) at $15(\bullet), 30(\boldsymbol{\Delta}), 45(\bullet)$ or $60^{\circ} \mathrm{C}(\boldsymbol{\nabla})$ over saturated $\mathrm{MgCl}_{2}(30 \% \mathrm{RH})$, either intermittently $\left(8 \mathrm{~h} \mathrm{day}^{-1}\right.$; A, B) or continuously $\left(24 \mathrm{~h} \mathrm{day}^{-1}\right.$; C, D), for rice accession IRGC 117265 harvested on 3 April 2015 (harvest A) or 16 April 2015 (harvest B) after 25, 35 or 45 days after 50\% anthesis (DAA). After these initial treatments seeds were dried further in the drying room $\left(15^{\circ} \mathrm{C} / 15 \% \mathrm{RH}, 11\right.$ days). Interrupted lines show loss in moisture content for seeds dried throughout in the drying room (DR) control $\left(15^{\circ} \mathrm{C} / 15 \% \mathrm{RH} ; \circ\right)$. Loss in moisture content during drying was estimated based on the initial determination and subsequent change in sample weight. Seed longevity at $45^{\circ} \mathrm{C}$ and $60 \% \mathrm{RH}\left(p_{50}\right.$; days \pm s.e.m.) after each drying treatment, provided by the best-fit model for each sample (DAA $\times$ temperature) for intermittent $(\mathrm{E}, \mathrm{F})$ or continuous drying $(G, H)$, is also shown. For clarity, the control values (open circles joined by broken lines) in E and $F$ are repeated in $G$ and $\mathrm{H}$, respectively. 
In this experiment, all rice seeds were metabolically active ( $\mathrm{MC}>16.2 \%$; Whitehouse et al., 2015) and assumed to have reached mass maturity before harvest (Kameswara Rao and Jackson, 1996a,b). Hence they were still within the desiccation phase of seed development where seed quality traits can still be accrued (Galau et al., 1991; Angelovici et al., 2010; Chatelain et al., 2012). In accordance with this, and similar to other studies (Ellis et al., 1993; Kameswara Rao and Jackson, 1996a,b; Hay and Smith, 2003; Ellis, 2011), the longevity of seeds dried in the drying room (control; broken lines) increased the later the seeds were harvested i.e. 25-35 DAA (Fig. 2E,G) until, depending on the environmental conditions, longevity plateaued (Fig. 3B) or declined (Fig. 2 F,H). However, as previously shown by Whitehouse et al. (2015), longevity continued to increase ex planta when seeds from both cultivars and all harvests were exposed to initial drying at temperatures $>15^{\circ} \mathrm{C}$ (Figs 2 and 3). The longevity of seeds dried intermittently or continuously for 3 days over $\mathrm{MgCl}_{2}(30 \% \mathrm{RH})$ continued to increase with drying at 30 to $45^{\circ} \mathrm{C}$ (Fig. 2E-H), with a further increase seen from 45 to $60^{\circ} \mathrm{C}$ in 'Macassane' seeds dried for 1 day over silica (Fig. 3B). The latter corresponds with the report that mature rice seeds can survive drying temperatures as high as $60^{\circ} \mathrm{C}$ (Lewis, 1950). As reported by Whitehouse et al. (2015), these results provide further confirmation that the quality of the seeds cannot be accurately predicted post mass maturity with respect to developmental time (DAA), as the pre-harvest environment (ambient temperature and humidity conditions, as well as the seed production environment) can restrict the seeds' progression through development and through maturation drying in particular.

Research has shown that the environmental conditions experienced during development and maturation can affect the relative timings of developmental stages (Hirano, 1979; Tu et al., 1988; Olivares et al., 2009; Ellis, 2011; Martínez-Eixarch and Ellis, 2015). For example, a warm seed production environment reduced the improvement in seed quality development that occurs subsequent to mass maturity in indica varieties of rice as the hotter temperatures enhanced the progression through development, which subsequently resulted in seeds that had not fully acquired maximum quality (Ellis et al., 1993). Continuation of such developmental events can, however, continue ex planta if seeds are held at conditions similar to those they would naturally encounter in situ (Hay and Probert, 1995; Hay, 1997; Probert et al., 2007). Rice seeds typically experience field temperatures between 27 and $30^{\circ} \mathrm{C}$ and so perhaps it is not surprising that subsequent longevity improved ex planta in response to drying at temperatures $>15^{\circ} \mathrm{C}$ (Figs 2E-H and 3B) However, improvements in seed quality are not infinite and presumably there is a 'maximum longevity' that any developing cohort of seeds can attain. A typical developmental response would involve a continual increase in longevity before plateauing, and although increases in longevity would be slower at temperatures cooler than $45-60^{\circ} \mathrm{C}$, all seed lots would be expected to eventually reach the same level of longevity. This was not observed in this study; rather, drying rate and subsequent storage longevity both increased with the increase in drying temperature, when seed lots were dried over silica gel (Fig. 3). This suggests that desiccation shock is more likely to account for the variation in longevity, whilst not ruling out a small contribution from continued development as it is likely that the two are connected, i.e. the desiccation shock accelerates the developmental events associated with increase in longevity during maturation drying. However, as some seed lots dried at a similar rate e.g. $15^{\circ} \mathrm{C} / 15 \%$ $\mathrm{RH}$ and $45^{\circ} \mathrm{C} / 30 \%$ RH (Fig. 2C,D) but with substantial differences in longevity (Fig. 2G,H), and all seed lots generally showed the greatest benefit to longevity within the first $2 \mathrm{~h}$ of drying, which was greater at higher temperatures (Fig. 3), there is clearly an effect of temperature rather than desiccation alone.

High temperatures are thought to induce stress responses within seeds, similar to that which triggers maturation drying, which is likely to promote the metabolic processes and protective mechanisms associated with desiccation (since they both represent stresses), including synthesis of late embryogenesis abundant (LEA) proteins and heat shock proteins (HSPs), accumulation of raffinose family oligosaccharides, and activation of anti-oxidant defence mechanisms (Vertucci and Farrant, 1995; Kermode, 1997; Bailly et al., 2004; Buitink and Leprince, 2008; Leprince and Buitink, 2010); high temperature will also increase the rate at which the above occur. This is supported by previous studies which provided evidence that the accumulation of soluble carbohydrates and heat stable proteins during development were associated with desiccation tolerance and potential longevity (Sinniah et al., 1998). However, these metabolic pathways and processes involved in the accumulation of longevity can be slowed/impaired when temperatures pass a critical limit (McDonald, 1999; Corbineau et al., 2002). Seed temperature during high-temperature drying would have increased towards the air temperature, albeit with some delay due to evaporative cooling as moisture was lost from the seeds; this may explain why seeds still benefit from drying at higher temperatures, up to $45^{\circ} \mathrm{C}$, even after 3 days, but also why longevity was greatest when seeds were dried for 1 day at $60^{\circ} \mathrm{C}$ (Fig. 3B) but not after 3 days (Fig. 2E-H). Furthermore, it is possible that normal energy metabolism and enzyme activity may have been reinstated in metabolically active seeds ( $>16.2 \% \mathrm{MC})$ during the non-drying period, as reported by Corbineau et al. (2002), which may explain the greater longevity 
observed in seeds dried intermittently at $60^{\circ} \mathrm{C}$ compared with seeds dried continuously (Fig. 2E-H).

Interestingly, prior to the 1990s, it was common practice to dry rice seeds intended for storage in the IRG at high temperature $\left(45-50^{\circ} \mathrm{C}\right)$ and it was only after the publication of the FAO genebank standards (FAO, 1994), which recommended cool temperatures combined with relatively low humidity to dry seeds prior to storage, that the drying room facility was installed and operated at $15^{\circ} \mathrm{C}$ and $15 \% \mathrm{RH}$. The standards were derived based on the low MC limit, i.e. below which there is no further improvement in longevity (Ellis and Hong, 2006 and references therein), and the drying conditions necessary to achieve this equilibrium MC (without jeopardising seed quality). The FAO wanted a single, simple, safe procedure for diverse species from all locations worldwide and due to the vulnerability of some species to high temperatures, especially when mature seeds were at high MC (Nellist, 1980; Cromarty et al., 1982; McDonald and Copeland, 1997), low temperature and humidity conditions were adopted (FAO, 1994, 2013). The genebank standards have recently been modified from $10-25^{\circ} \mathrm{C}$ and $10-15 \% \mathrm{RH}(\mathrm{FAO}, 1994)$ to a lower temperature $\left(5-20^{\circ} \mathrm{C}\right)$ and broader humidity $(10-25 \% \mathrm{RH})$ range $(\mathrm{FAO}, 2013)$ that further contradicts the results presented in this study which show drying rice seeds, harvested before maturity, at higher temperatures and at a higher humidity $(30 \% \mathrm{RH})$ can significantly improve their subsequent storage longevity by more than that which occurred during subsequent development in planta. This could benefit farmers in resource-limited countries, particularly those in wet tropical regions, where it is difficult to dry large volumes of seeds to low MC. The quality of freshly harvested seeds could be maintained better (e.g. to the next growing season) by drying seeds to an intermediate MC using heated air.

To conclude, there is clear evidence that drying freshly harvested, high moisture content rice seeds under low temperature, low humidity conditions is not optimum for subsequent seed storage longevity. Rice seeds showed improvement in longevity in response to drying for a total of 3 days at temperatures greater than $15^{\circ} \mathrm{C}$, up to at least $45^{\circ} \mathrm{C}$ (but drying at $60^{\circ} \mathrm{C}$ for more than 1 day may damage some seeds). Further studies could involve testing, in independent studies, the beneficial limits of high-temperature drying on rice seeds produced/regenerated in other climatic regions. This could have huge implications on how rice seeds are managed by genebanks globally to ensure maximum longevity when first placed into storage. However, future research should investigate high-temperature drying of fresh moist seeds more widely, addressing other economically important crops, especially those with poor seed storage longevity and where harvesting seeds at a range of maturities and hence, perhaps moisture content, is inevitable.

\section{Financial support}

This research received no specific grant from any funding agency, commercial or non-for-profit sectors.

\section{Supplementary material}

To view supplementary material for this article, please visit https://doi.org/10.1017/S0960258517000277.

\section{References}

Angelovici, R., Galili, G., Fernie, A.R. and Fait, A. (2010) Seed desiccation: a bridge between maturation and germination. Trends in Plant Science 15, 211-218.

Bailly, C., Leymaries, J., Lehner, A., Rousseau, S., Côme, D. and Corbineau, F. (2004) Catalase activity and expression in developing sunflower seeds as related to drying. Journal of Experimental Botany 55, 475-483.

Buitink, J. and Leprince, O. (2008) Intracellular glasses and seed survival in the dry state. Comptes Rendus Biologies 331, 788-795.

Chatelain, E., Hundertmark, M., Leprince, O., Le Gall, S., Satour, P., Deligny-Pennick, S., Rogniaux, H. and Buitink, J. (2012) Temporal profiling of the heat-stable proteome during late maturation of Medicago trunculata seeds identifies a restricted subset of late embryogenesis abundant proteins associated with longevity. Plant Cell and Environment 35, 1440-1455.

Chen, H., Siebenmorgen, T.G. and Marks, B.P. (1997) Relating the drying rate constant to head rice yield reduction in long-grain rice. Transactions of the American Society of Agricultural Engineers 40, 1133-1139.

Cnossen, A.G. and Siebenmorgen, T.G. (2000) The glass transition temperature concept in rice drying and tempering: effect of milling quality. Transactions of the American Society of Agricultural Engineers 43, 1661-1667.

Cnossen, A.G. and Siebenmorgen, T.G. (2002) The glass transition temperature concept in rice drying and tempering: effect on drying rate. Transactions of the American Society of Agricultural Engineers 45, 759-766.

Coast, O., Ellis, R.H., Murdoch, A.J., Quiñones, C. and Jagadish, K.S.V. (2015) High night temperature induces contrasting responses for spikelet fertility, spikelet tissue temperature, flowering characteristics and grain quality in rice. Functional Plant Biology 42, 149-161.

Collinson, S.T., Ellis, R.H., Summerfield, R.J. and Roberts, E.H. (1992) Duration of the photoperiod-sensitive and photoperiod-insensitive phases of development to flowering in four cultivars of rice. Annals of Botany 70, 339-346.

Corbineau, F., Gay-Matheiu, C., Vinel, D. and Côme, D. (2002) Decrease in sunflower (Helianthis annus) seed viability caused by high temperature as related to energy metabolism, membrane damage and lipid composition. Physiologica Plantarum 116, 489-496.

Cromarty, A.S., Ellis, R.H. and Roberts, E.H. (1982) The design of seed storage facilities for genetic conservation. Rome, International Board for Plant Genetic Resources.

Ellis, R.H. (2011) Rice seed quality development and temperature during late development and maturation. Seed Science Research 21, 95-101. 
Ellis, R.H. and Hong, T.D. (1994) Desiccation tolerance and potential longevity of developing seeds of rice (Oryza sativa L.). Annals of Botany 73, 501-506.

Ellis, R.H. and Hong, T.D. (2006) Temperature sensitivity of the low-moisture-content limit to negative seed longevity-moisture content relationships in hermetic storage. Annals of Botany 97, 785-791.

Ellis, R.H. and Roberts, E.H. (1980) Improved equations for the prediction of seed longevity. Annals of Botany 45, 13-30.

Ellis, R.H., Hong, T.D. and Roberts, E.H. (1989) A comparison of the low-moisture-content limit to the logarithmic relation between seed moisture and longevity in twelve species. Annals of Botany 63, 601-611.

Ellis, R.H., Hong, T.D. and Roberts, E.H. (1992) The low moisture content limit to the negative logarithmic relation between seed longevity and moisture content in three subspecies of rice. Annals of Botany 69, 53-58.

Ellis, R.H., Hong, T.D. and Jackson, M.T. (1993) Seed production environment, time of harvest, and the potential longevity of seeds of three cultivars of rice (Oryza sativa L.). Annals of Botany 72, 583-590.

Evans, L.T. (1993) Crop Evolution, Adaption and Evolution. Cambridge University Press, Cambridge, UK.

FAO/IPGRI (1994) Genebank standards. Rome, Food and Agriculture Organisation of the United Nations/ International Plant Genetic Resources Institute.

FAO (2013) Genebank standards for plant genetic resources for food and agriculture. Rome, Food and Agriculture Organization of the United Nations.

Galau, G.A., Kjetill, S.J. and Hughes, D.W. (1991) The controls of the late dicot embryogenesis and early germination. Plant Physiology 81, 280-288.

Hay, F.R. (1997) The development of seed longevity in wild plant species. PhD thesis, University of London, UK.

Hay, F.R. and Probert, R.J. (1995) Seed maturity and the effects of different drying conditions on the desiccation tolerance and seed longevity in foxglove (Digitalis purpurea L.). Annals of Botany 76, 639-647.

Hay, F.R. and Smith, R.D. (2003) Seed maturity: when to collect seeds from wild plants, pp. 97-133 in Smith, R.D., Linington, S.H., Dickie, J.B., Pritchard, H.W. and Probert, R.J. (eds), Seed Conservation: Turning Science into Practice. Royal Botanic Gardens, Kew, Richmond, UK.

Harrington, J.F. (1972) Seed storage and longevity, pp. 145-245 in Kozlowski, T.T. (ed), Seed Biology, Vol. III. New York, Academic Press.

Hirano, J. (1979) The effects of rain ripening period on the grain quality of wheat. Japan Agricultural Research Quarterly 10, 169-173.

Jagadish, S.V.K., Craufurd, P.Q. and Wheeler, T.R. (2008) Phenotyping parents of mapping populations of rice for heat tolerance during anthesis. Crop Science 48, 11401146.

ISTA (2013) International rules for seed testing. Basserdorf, International Seed Testing Association.

Jittanit, W., Srzednicki, G. and Driscoll, R. (2010) Corn, rice and wheat seed drying by two-stage concept. Drying Technology 28, 807-815.

Kameswara Rao, N. and Jackson, M.T. (1996a) Seed longevity of rice cultivars and strategies for their conservation in genebanks. Annals of Botany 77, 251-260.

Kameswara Rao, N. and Jackson, M.T. (1996b) Seed production environment and storage longevity of japonica rice (Oryza sativa L.). Seed Science Research 6, 17-21.
Kermode, A.R. (1997) Approaches to elucidate the basis of desiccation-tolerance in seeds. Seed Science Research 7, 75-95.

Leprince, O. and Buitink, J. (2010) Desiccation tolerance: from genomics to the field. Plant Science 179, 554-564.

Lewis, R.D. (1950). Agricultural research in Texas, 1947-49. Texas, Texas Agricultural Experiment Station.

Martínez-Eixarch, M. and Ellis, R.H. (2015) Relative temporal sensitivity of rice seed development from spikelet fertility to viable mature seed to low-or to hightemperature stress. Crop Science 55, 354-364.

McDonald, M.B. (1999) Seed deterioration: physiology, repair and assessment. Seed Science and Technology 27, 177-237.

McDonald, M.B. and Copeland, L. (1997) Seed Production: Principles and Practices. New York, Chapman \& Hall.

McNally, K.L., Child, K.L., Bohnert, R., Davidson, R.M., Zhao, K., Ulat, V.J., Zeller, G., Clark, R.M., Hoen, D. R., Bureau, T.E., Stokowski, R., Ballinger, D.G., Frazer, K.A., Cox, D.R., Padhukasahasram, B., Bustamante, C.D., Weigel, D., Mackill, D.J., Bruskiewich, R.M., Ratsch, G., Buell, C.R., Leung, H. and Leach, J.E. (2009) Genomewide SNP variation reveals relationships among landraces and modern varieties of rice. PNAS 30, 12273-12278.

Mead, A. and Gray, D. (1999) Prediction of seed longevity: a modification of the shape of the Ellis and Roberts seed survival curves. Seed Science Research 9, 63-73.

Nellist, M.E. (1980) Safe drying temperatures for seed grain, pp. 371-388 in Hebblethwaite, P.D. (ed), Seed Production. London, Butterworth.

Olivares, A., Johnston, M. and Calderon, C. (2009) Effect of rainfall regimes on seed production and quality of Avena barbata. Ciencia e Investigacion Agraria 36, 69-76.

Probert, R.J., Adams, J., Coneybeer, J., Crawford, A. and Hay, F. (2007) Seed quality for conservation is critically affected by pre-storage factors. Australian Journal of Botany 55, 326-335.

Rao, N.K., Hanson, J., Dulloo, M.E., Ghosh, K., Nowell, D. and Larinde, M. (2006) Manual of seed handling in genebanks. Handbooks for genebanks, No. 8. Rome, Bioversity International.

Regalado, M.J. and Brena, S.R. (2006) The influence of drying methods and storage conditions on the seed viability and longevity of Mestizo hybrid rice (Oryza sativa L.). The Philippine Agricultural Scientist 89, 309-318.

Schluterman, D.A. and Siebenmorgen, T.J. (2007) Relating rough rice moisture content reduction and tempering duration to head rice yield reduction. Transactions of the American Society of Agricultural Engineers 50, 137-142.

Sinniah, U.R., Ellis, R.H. and John, P. (1998) Irrigation and seed quality development in rapid-cycling Brassica: soluble carbohydrates and heat-stable proteins. Annals of Botany 82, 647-655.

Tu, J.C., McDonnell, M. and Dirks, V.A. (1988) Factors affecting seed quality of navy bean in the field in South Western Ontario. Seed Science and Technology 16, 371-381.

Vertucci, C.W. and Farrant, J.M. (1995) Acquisition and loss of desiccation tolerance, pp. 237-271 in Kigel, J. and Galili, G. (eds), Seed Development and Germination. New York, Marcel Dekker Inc.

Wassman, R., Jagadish, S.V.K., Sumfleth, K., Pathak, H., Howell, G., Ismail, A., Serraj, R., Redona, E., Singh, R. K. and Heuer, S. (2009) Regional vulnerability of climate 
change impacts on Asian rice production and scope for adaptation. Advance in Agronomy 102, 91-133.

Whitehouse, K.J., Hay, F.R. and Ellis, R.H. (2015) Increases in the longevity of desiccation-phase developing rice seeds: response to high-temperature drying depends on harvest moisture content. Annals of Botany 116, 245-259.

Yamashita, R. (1993) New technology in grain postharvesting, pp. 208 in Yamashita, R. (ed), Farm Machinery Industrial Research Corporation. Tokyo.
Yin, X., Kropff, M.J. and Ellis, R.H. (1996) Rice flowering in response to diurnal temperature amplitude. Field Crops Research 48, 1-10.

Yoshida, S. (1981) Fundamentals of Rice Crop Science. International Rice Research Institute, Los Baños, Philippines.

Zhang, Z., Su, L., Li, W., Chen, W. and Zhu, Y. (2005) Major QTL conferring cold tolerance at early seedling stage using recombinant inbred lines of rice (Oryza sativa L.). Plant Science 168, 527-534. 